\title{
Doğu Anadolu Projesi Bölge Kalkınma İdaresinde Yer Alan Organize Sanayi Bölgelerinin Etkinlik Değerlendirmesi
}

\author{
Efficiency Evaluation of Organized Industrial Zones in East Anatolian Project Regional \\ Development Administration
}

\author{
Mehtap DURSUN* \\ Galatasaray Üniversitesi, Mühendislik ve Teknoloji Fakültesi, Endüstri Mühendisliği Bölümü, İstanbul, Türkiye
}

\begin{abstract}
• Geliş tarihi / Received: 30.11.2017 • Düzeltilerek geliş tarihi / Received in revised form: 27.05.2019 • Kabul tarihi / Accepted: 13.09 .2019
\end{abstract}
$\ddot{O} \mathbf{z}$

Organize sanayi bölgeleri (OSB), sanayinin uygun alanlarda yapılandırılması, çevre sorunlarının önlenmesi ve kaynakların etkin kullanımı için planlı sanayileşme ve planlı kentleşme sağlamak amacıyla kurulan üretim alanlarıdır. OSB'ler, 1960'lardan beri Türk hükümeti tarafından kurulmaya ve desteklenmeye başlanmıştır. Günümüzde Türkiye'nin tüm şehirlerinde (Artvin hariç) bir veya daha fazla OSB bulunmaktadır. Bu OSB'lerin düşük doluluk oranları, OSB'lerin etkin çalışıp çalışmadığı sorusunu gündeme getirmektedir. Bu çalışma, Doğu Anadolu Projesi Bölge Kalkınma İdaresinde yer alan OSB'lerin etkinliklerini, karar verme birimlerinin göreli etkinliklerini ölçmek için güçlü bir yöntem olan veri zarflama analizi (VZA) temelli modeller kullanarak değerlendirmeyi amaçlamaktadır.

Anahtar kelimeler: Çok ölçütlü karar verme, Karar destek sistemleri, Organize sanayi bölgeleri, Performans değerlendirme, VZA temelli modeller

\begin{abstract}
Organized industrial zones (OIZs) are the production areas of goods and services that are established to provide planned industrialization and planned urbanization by structuring the industry in suitable areas, to prevent environmental problems and to provide efficient use of resources. Organized Industrial Zones (OIZs) have been established in 1960s for planned industrialization and planned urbanization. Recently, there are one or more OIZs in all cities of Turkey (except Artvin). The low occupancy rates of these OIZs make the question of whether the OIZs work efficiently. This study aims to evaluate the efficiencies of OIZs in East Anatolian Project Regional Development Administration by using data envelopment analysis (DEA) based decision models, which are powerful methods to measure the relative efficiencies of decision making units.
\end{abstract}

Keywords: Multi-criteria decision-making, Decision support systems, Organized industrial zones, Performance evaluation, DEA based decision model

*Mehtap DURSUN; mdursun@ @su.edu.tr; Tel: (0505) 50710 49; orcid.org/0000-0002-7684-0319 


\section{Giriş}

Türkiye'de sanayileşme çabaları Cumhuriyetin kurulması ile birlikte artış göstermeye başlamış ve yeni kazanılan siyasi bağımsızlığın ve ekonomik kalkınmanın temeli olarak görülmüştür. Cumhuriyetin ilk yıllarında sanayileşme özel sektör girişimlerine bırakılmış ancak finansal güç ve tecrübe eksikliği gibi sebeplerle özel sektör bu görevi yeterince yerine getirememiş, devlet desteğine ihtiyaç duyulmuştur. Sanayileşme çabalarını takiben sanayileşme altyapı çalışmaları 1931'de oluşturulan "I. Beş Yıllık Kalkınma Planı" ile başlamıştır. 1960'da başlayan planlı kalkınma döneminde ise lokomotif sektör olarak görülmeye başlanan sanayiye yönelik hedefler artırılmıştır (URL 1, 2016).

1960'lı yıllarda planlı sanayileşme ve planlı kentleşmenin sağlanması amacıyla devlet tarafindan Organize Sanayi Bölgeleri (OSB) ve Küçük Sanayi Siteleri kurulmaya başlanmış ve özellikle organize sanayi bölgelerinde yer alan yatırımcılara güçlü destek ve teşvikler sunulmuştur (Cansız, 2010).

Organize Sanayi Bölgeleri;

- Sanayinin uygun alanlarda yapılandırılması, çevre sorunlarının önlenmesi, kaynakların verimli kullanılması ile planlı sanayileşme ve planlı kentleşmeyi sağlamak üzere kurulan,

- Gerekli idari, sosyal ve teknik altyapı alanları ile küçük imalat, tamir, ticaret, eğitim ve sağlık alanları, teknoloji geliştirme bölgeleri ile donatilan,

- 4562 Sayılı Organize Sanayi Bölgeleri Kanunu'na göre işletilen mal ve hizmet üretim bölgeleridir (URL-2, 2016).

Türkiye'deki tüm OSB'lerin izleme ve değerlendirme çalışmaları Bilim, Sanayi ve Teknoloji Bakanlığı tarafından yapılmaktadır. Bilim, Sanayi ve Teknoloji Bakanlı̆̆ı'nın 01.03.2017 tarihli verilerine göre toplamda 297 adet OSB'de 49.877 sanayi parselinde üretime geçilmiştir ve 1.658 .835 kişiye istihdam sağlanmaktadır. Ancak mevcut OSB'lerde üretimdeki parseller dışında boş parseller de bulunmaktadır ve bazı OSB'lerde boş parsel oranı oldukça yüksektir.

Türkiye'deki OSB'lerin ortalama doluluk oranı (Tahsis Edilen Parsel Say1s1/Toplam Parsel Say1s1) \%68'dir ve yüksek bir oran olduğu söylenemez. Diğer bir gösterge olan üretimdeki parsel oranına (Üretime Geçilmiş Parsel Sayısı/Toplam Parsel Sayısı) bakıldığında ise \%43 olduğu görülmektedir ve daha düşük bir orandır. $\mathrm{Bu}$ oranlar göz önünde bulundurulduğunda OSB'lerin istenen etkinlik düzeyine ulaşıp ulaşamadığ sorgulanması gereken bir konudur. Bölgesel farklılıklardan kaynaklanan etkileri en aza indirgemek için etkinlik analizinin bölgesel bazda yapılması elde edilen sonuçların güvenilirliğini arttırmaktadır. Bu bağlamda, bu çalışmada Doğu Anadolu Projesi Bölge Kalkınma İdaresinde yer alan OSB'lerin karşılaştırmalı etkinlikleri değerlendirilecektir. Homojen birimlerin göreli etkinliğini elde etmek için birimlerin ortak girdi ve çıktılarını kullanan veri zarflama analizi (VZA) temelli yaklaşımlar kullanılarak OSB'ler için etkinlik analizi yapılacak ve elde edilen sonuçlar irdelenecektir. VZA girdi ve çıktı ölçütlerinin aynı ölçüm birimlerinde olmalarını gerektirmez ve girdi ve çıktı ölçütleri için önceden belirlenmiş ağırlıklara ihtiyaç duymaz. $\mathrm{Bu}$ sebeple etkinlik değerlendirmede yaygın olarak kullanılan bir yöntemdir.

Çalışmanın 2. Bölümünde sanayi bölgeleri ve sanayi bölgelerinde faaliyet gösteren firmalarının etkinliğine dair yapılmış VZA çalışmalarından bahsedilmektedir. Bölüm 3'te VZA ve VZA temelli modeller açıklanmaktadır. Doğu Anadolu Projesi Bölge Kalkınma İdaresinde yer alan OSB'lerin etkinlik analizi Bölüm 4'te gösterilmekte ve son olarak çalışmanın sonuçları Bölüm 5'te paylaşılmaktadır.

\section{Literatür Araștırması}

Bir kurumun/kuruluşun ya da bir birimin etkinliği değerlendirilirken birç̧ok ölçüt aynı anda ele alınmaktadır. Veri Zarflama Analizi (VZA) karar verme birimlerinin göreli etkinliğini ölçmek için birimlerin ortak girdi ve çıtılarını ölçüt olarak kullanan bir matematiksel programlama yöntemidir. Çalışmanın bu bölümünde sanayi bölgeleri ve sanayi bölgelerinde faaliyet gösteren firmalarının etkinliğine dair yapılmış VZA çalışmalarından bahsedilmektedir.

$\mathrm{Hu}$ vd. (2010) bilim ve teknoloji sanayi parklarının (BTSP) performanslarını değerlendirmek amaciyla Fried vd. (1999) tarafindan önerilen dört aşamalı VZA metodunu kullanmıştır. Çalışma için Çin'de yer alan BTSP'lerin 2004-2006 yılları arası verileri göz önünde bulundurulmuştur. BTSP'lerin etkinliklerinin sağlıklı bir şekilde ölçülebilmesi için girdi ve çıtı değişkenlerinin değerlendirildiği dört aşamalı VZA dışında çevresel faktörlerin değerlendirilmesi de çalışmaya dahil edilmiştir. 
Yenilmez ve Girginer (2012) çıkt1 maksimizasyonunu amaçlayan VZA metodu uygulamasıyla Eskişehir Organize Sanayi Bölgesi'nde yer alan ihracatçı tekstil firmalarının etkinliklerini araştırmıştır. Firmaların göreli etkinliğinin ölçülmesi için 5 ihracatçı firmanın 2008-2009 yılları girdi ve çıktı verileri kullanılmıştır.

Hu vd. (2009) 2004 ve 2006 yıllar1 arasinda Tayvan'daki 57 sanayi bölgesinin performansını analiz etmek için VZA yöntemini kullanmıştır. Çalışmada etkinlik değerleri karşılaştırılmış ve tüm sanayi bölgeleri bu değerlere göre sıralanmıştır.

Khodakarami vd. (2014) kademeli etkinlik iyileştirme VZA modeli geliştirmiş ve modeli 31 İran sanayi bölgesi verisine uygulamıștır. Bu çalışmada sanayi bölgelerinin sürdürülebilirlikleri analiz edilmeye çalışılmıştır. Çevresel performans öncü ve diğer sanayi bölgelerini belirlemek için kullanılmış ve etkinliği düşük olanlar öncülerin etkinliğine kademeli olarak yaklaştırılmaya çalışılmıştır.

Izadikhah ve Saen (2015) tüm etkin karar verme birimlerinin sıralanmasını sağlayacak olan yeni bir VZA modeli önermiştir. Geliştirilen yeni model İran'daki 17 sanayi parkına uygulanmıştır.

Liu vd. (2015) Çin'deki eko-sanayi parklarının çevresel performansını analiz etmek için VZA temelli bir ağırlıklandırma yaklaşımını kullanmıştır. Önerilen yaklaşım Çin'deki 34 ekosanayi bölgesinin 2007-2010 y1lları verisine uygulanmıştır.

Chen vd. (2017) Çin'in Yangtze Nehri Ekonomik Bölgesinde yer alan 131 ülkenin çevresel etkinliğini süper etkin VZA modeli kullanarak değerlendirmiştir.

Fan vd. (2017) Çin'de yer alan 40 endüstriyel parkın çevresel etkinliğini VZA modelini kullanarak belirlemiştir.

\section{Veri Zarflama Analizi Temelli Modeller}

Charnes vd. (1978) tarafından geliştirilen veri zarflamas1 analizi, homojen birimlerin karşılaştırmalı etkinliklerini elde etmek için ortak girdi ve çıktıları ölçüt olarak kullanan matematiksel bir programlama modelidir. Etkinlikleri değerlendirilen homojen birimler genellikle karar verme birimleri (KVB) olarak adlandırılır.
VZA, girdi ve çıktı değerlerini kullanarak etkinlik sınırları oluşturmaktadır. Bir KVB sınırlardan birinin üzerinde ise etkin, sınırların içindeyse etkin değildir. VZA, ağırlıklı çıktıların toplamının ağırlıklı girdilerin toplamına oranını, etkinlik sınırının ötesinde herhangi bir KVB'nin etkin olamayacağı kısıtlaması altında maksimize etmeyi amaçlamaktadır (Façanha ve Resende, 2004).

Etkinlik analiz yöntemlerinin çoğu, ölçütler için aynı ölçüm birimlerine ve önceden belirlenmiş ağırlıklara ihtiyaç duymaktadır. Etkinlik analizinde bu zorlukların üstesinden gelebilen bu yöntem ilk önce kar amacı gütmeyen işletmelerin karşılaştırmalı etkinlikleri ölçmek için kullanılmış ve daha sonra kar odakl üretim ve hizmet sektörlerinde ortak bir kullanım alanı bulmuştur (Yolalan, 1993).

Charnes vd. (1994) DEA'nın avantajlarını şu şekilde belirmektedir.

- Çoklu girdiler ve çoklu çıktılar, farklı ölçüm birimlerine sahip olsalar bile değerlendirilebilir,

- Kategorik değişkenler içerebilir,

- Girdiler ve çıktılar için önceden ağırlık belirlemek gerekmez,

- Etkin olmayan KVB'leri etkin sinıra yükseltmek için değişiklikler önerilebilir,

- Pareto optimal sonuçlar üretir,

- Sonuç üretirken "merkezi eğilim" yerine "en iyiye" odaklanmaktadır.

Belirtilen avantajlardan dolayı metot sağlık, ulaşım, yazılım ve finans endüstrisi gibi pek çok alanda yaygın olarak kullanılmaktadır.

Charnes vd. (1978) tarafindan önerilen, CCR modeli olarak da adlandırılan orijinal VZA modeli, her KVB için çıktının girdiye oranının bire eşit veya daha az olması koşuluyla, toplam ağırlıklı çıktının toplam ağırlıkl girdiye oranını maksimize ederek bir KVB'nin göreceli etkinliğini hesaplar. Geleneksel VZA formülasyonu aşağıdaki gibi gösterilmektedir (Charnes vd., 1978):

$\max E_{j_{0}}=\frac{\sum_{r} u_{r} y_{r j_{0}}}{\sum_{i} v_{i} x_{i j_{0}}}$

$\frac{\sum_{r=1}^{s} u_{r} y_{r j}}{\sum_{i=1}^{m} v_{i} x_{i j}} \leq 1, \quad \forall j$,
$u_{r}, v_{i} \geq \varepsilon, \quad \forall r, i$. 
Gösterimde, sirasiyla, $\quad E_{j_{0}} \quad \mathrm{E}_{\mathrm{J} 0}$ değerlendirilen KVB'nin etkinlik değerini, $u_{r} r$ çıktısına atanan ağırlığı, $\quad v_{i} i$ girdisine atanan ağırlığı, $\quad y_{r j}$ $\mathrm{y}_{\mathrm{rj}}$ üretilen çıktı miktarını, $x_{i j} j$ ninci KVB tarafından tüketilen girdi miktarını ve $\varepsilon$ küçük bir pozitif sayıyı göstermektedir.

Formülasyon (1) doğrusal ve konveks olmayan özelliklere sahiptir, ancak doğrusal programlama modeline dönüștürülebilir. Bir KVB'nin göreli etkinliğini hesaplamak için doğrusal programlama modeli formülasyon (2)'de verilmektedir.

$$
\begin{aligned}
& \max E_{j_{0}}=\sum_{r} u_{r} y_{r_{j_{0}}} \\
& \sum_{i} v_{i} x_{i j_{0}}=1 \\
& \sum_{r=1}^{s} u_{r} y_{r j}-\sum_{i=1}^{m} v_{i} x_{i j} \leq 0, \quad \forall j, \\
& u_{r}, v_{i} \geq \varepsilon, \quad \forall r, i .
\end{aligned}
$$

Geleneksel VZA-CCR modelinin birçok olumlu yönü olmasına rağmen, bazı eksiklikleri de mevcuttur. Bu dezavantajların üstesinden gelmek için pek çok yeni yaklaşım önerilmiştir. Geleneksel VZA modelinin eksikliklerinden birisi, değerlendirilen KVB için yüksek etkinlik skoru üretmek için girdilere ve çıktılara gerçekçi olmayan ağırlıklar ataması ve dolayısıyla etkin KVB'lerin sayısının oldukça yüksek olabilmesidir. Minsum ve minimax etkinlik modelleri (Li ve Reeves, 1999), bu sorunun üstesinden gelmek için geliştirilen modellerdendir. Minsum etkinlik modeli, her bir KVB için etkinlikten sapmaların toplamını en aza indirmeyi amaçlamakta ve aşağıdaki gibi gösterilmektedir.

$$
\begin{aligned}
& \min \sum_{j=1}^{n} d_{j} \\
& \sum_{i=1}^{m} v_{i} x_{i j_{0}}=1, \\
& \sum_{r=1}^{s} u_{r} y_{r j}-\sum_{i=1}^{m} v_{i} x_{i j}+d_{j}=0, \quad \forall j, \\
& u_{r}, v_{i}, d_{j} \geq 0, \quad \forall r, i, j .
\end{aligned}
$$

$\mathrm{Bu}$ gösterimde $d_{j} j$ ninci $\mathrm{KVB}$ için sapma değişkenidir. $\mathrm{KVB}_{0}$ '’n minsum etkin olması için, etkinlikten sapmaların toplamını en aza indirgeyen çözüme tekabül eden $d_{0}\left(\mathrm{KVB}_{0}\right.$ için sapma değişkeni) değerinin sıfır olaması gerekmektedir. $\mathrm{Bu}, \mathrm{KVB}_{0}$ 'ın yalnızca $d_{0}=0$ veya eşdeğer olarak $h_{0}=1 \quad\left(h_{0} \quad \mathrm{KVB}_{0}\right.$ için etkinlik değeridir) olduğu durumlarda etkin olduğu anlamına gelir. $\mathrm{KVB}_{0}$ etkin değilse etkinlik değeri $h_{0}=1-d_{0}$ olarak hesaplanır.

Minimax etkinlik modeli, etkinlikten en fazla sapmayı en aza indirmeyi amaçlamakta ve aşağıdaki gibi gösterilmektedir.

\section{$\min M$}

$$
\begin{aligned}
& \sum_{i=1}^{m} v_{i} x_{i j_{0}}=1, \\
& \sum_{r=1}^{s} u_{r} y_{r j}-\sum_{i=1}^{m} v_{i} x_{i j}+d_{j}=0, \quad \forall j, \\
& M-d_{j} \geq 0, \quad \forall j, \\
& u_{r}, v_{i}, d_{j} \geq 0, \quad \forall r, i, j .
\end{aligned}
$$

$\mathrm{Bu}$ gösterimde, $M$ etkinlikten en fazla sapmay1 göstermektedir. Etkinlik değeri hesaplamaları minsum etkinlik modeli ile aynıdır.

Minimax ve minsum modellerinde KVB'ler geleneksel DEA modelindeki etkin ve etkin olmayan KVB'ler olarak sinıflandirılır ve etkin KVB'lerin sayısı azaltılmaya çalıșılır, ancak genel olarak 1'e indirgenemez. Etkinlik sıralamas1, etkin olmayan KVB'ler için elde edilirken, etkin olmayan KVB'ler için sıralama mümkün değildir. Dolayısıyla, modellerin ayır edici gücü düşüktür.

$\mathrm{Bu}$ modellerin bir diğer eksikliği de " $n$ " kere hesaplama gerektirmesidir. Yani, veri setinde 100 KVB varsa, tüm KVB'ler için etkinlik değeri elde etmek için model 100 kez çözülmelidir.

Dahası, klasik VZA yönteminde her bir KVB için ayrı ayrı çözülen model, değerlendirilen KVB için etkinlik değerini en büyüklemek için değişkenlere farklı ağırlıklar atamaktadır. Değişkenlere atanan farklı ağırlıklar ile belirlenen KVB etkinlik değerleri, elde edilen sonucun güvenilirliğini etkilemektedir ve KVB'lerin hepsini aynı temelde değerlendirmeyi güçleştirmektedir.

$\mathrm{Bu}$ modellerin yanısıra, değerlendirilen KVB etkinlik değerinin biden fazla çıkmasına olanak sağlayan super etkinlik modeli de etkin KVB'leri sıralamak için önerilmiştir. $\mathrm{Bu}$ model 
Formülasyon (5)'teki gibi ifade edilebilir (Andersen ve Petersen, 1993).

$$
\begin{aligned}
& \max \sum_{r=1}^{s} u_{r} y_{r k} \\
& \sum_{i=1}^{m} v_{i} x_{i k}=1, \\
& \sum_{r=1}^{s} u_{r} y_{r j}-\sum_{i=1}^{m} v_{i} x_{i j} \leq 0, \quad \forall j, j \neq k \\
& u_{r}, v_{i} \geq \varepsilon, \quad \forall r, i .
\end{aligned}
$$

Süper etkinlik modelinin dezavantajları KVB'lere düzgün olmayan ağırlıklandırma vermesi, belirli bir KVB'ye oldukça yüksek etkinlik değeri ataması ve olurlu olamayan sonuçlar belirleyerek KVB'leri sıralayamaması olarak özetlenebilir (Adler vd., 2002).

$\mathrm{Bu}$ eksiklikleri ortadan kaldırmak için "ortak ağırlık tabanlı VZA modeller" geliştirilmiştir. Bu modeller tüm KVB'lerin girdi ve çıtı değişkenleri için ortak ağırlık oluşturmakta ve daha az hesaplama gerektirmektedir. Sun vd. (2013) tarafından geliştirilen ortak ağılık tabanlı VZA modeli aşağıdaki gibidir.

$$
\begin{aligned}
& \min \sum_{j=1}^{n} d_{j} \\
& \sum_{i=1}^{m} v_{i} x_{i j}-d_{j}=\sum_{r=1}^{s} u_{r} y_{r j}, \quad \forall j, \\
& \sum_{i=1}^{m} v_{i} x_{\min }=1 \\
& \sum_{r=1}^{s} u_{r} y_{\max }=1 \\
& u_{r}, v_{i} \geq \varepsilon, \quad \forall r, i, \\
& d_{j} \geq 0, \quad \forall j .
\end{aligned}
$$

Bu modelde,

$$
x_{\min }=\min \left\{x_{i j} \mid j=1, \ldots, n\right\},(i=1, \ldots, m)
$$

ve

$$
\begin{aligned}
& y_{\max }=\max \left\{y_{r j} \mid j=1, \ldots, n\right\},(r=1, \ldots, s) \mathrm{y}_{\max }= \\
& \max \left\{\mathrm{y}_{\mathrm{rj}} \mid \mathrm{j}=1, \ldots, \mathrm{n}\right\},(\mathrm{r}=1, \ldots, \mathrm{s}) \quad \text { olarak } \\
& \text { tanımlanmaktadır. }
\end{aligned}
$$

Formülasyon (6) ile hesaplanan optimal ağırlıklar genellikle tek olmadığı için Sun vd. (2013) aşağıda gösterilen doğrusal olmayan modeli geliştirmişlerdir.

$\max \sum_{i=1}^{m} v_{i}^{2}+\sum_{r=1}^{s} u_{r}^{2}$

$\sum_{j=1}^{n}\left(\sum_{i=1}^{m} v_{i} x_{i j}-\sum_{r=1}^{s} u_{r} y_{r j}\right)=D^{*}$
$\sum_{i=1}^{m} v_{i} x_{i j}-\sum_{r=1}^{s} u_{r} y_{r j} \geq 0, \quad \forall j$,

$\sum_{i=1}^{m} v_{i} x_{\min }=1$

$\sum_{r=1}^{s} u_{r} y_{\max }=1$,

$u_{r}, v_{i} \geq \varepsilon, \quad \forall r, i$.

Bu gösterimde $D^{*}$ formülasyon (6)'nın optimal amaç fonksiyonu değeridir. Etkinlik değerlerini hesaplamak için, model tarafindan belirlenen girdi ve çıktı ağırlıkları, ilgili girdi ve çıktı değerleri ile çarpılır ve her KVB için $\frac{\sum_{r=1}^{s} u_{r} y_{r j}}{\sum_{i=1}^{m} v_{i} x_{i j}} \frac{\sum_{\mathrm{r}=1}^{\mathrm{s}} \mathrm{u}_{\mathrm{r}} \mathrm{y}_{\mathrm{rj}}}{\sum_{\mathrm{i}=1}^{\mathrm{m}} \mathrm{v}_{\mathrm{i}} \mathrm{x}_{\mathrm{ij}}}$ formülasyonu kullanılır.

\section{Vaka Analizi}

Organize sanayi bölgeleri, firmalara toplu firsatlar sağlayan yapılar olup sanayinin güçlenmesine katkıda bulunmayı amaçlamaktadır. $\mathrm{Bu}$ yapılar hükümet tarafindan desteklenmekte ve yatırımcilar OSB'leri tercih etmeye teşvik edilmektedir. $\mathrm{Bu}$ noktada, birçok bakanlık OSB'leri, mevzuatlarında tanıdığı ayrıcalıklarla desteklemekte ve Türkiye'deki faaliyetlerini etkilemektedir. Ancak, her ilde kurulan ve devlet tarafindan desteklenen OSB'lerin doluluk oran1 istenilen düzeyde değildir. Bu durum, OSB'lerin etkinlik değerlendirmesi ihtiyacını ortaya çıkarmaktadır.

OSB'lerin hedeflerinden biri, bölgesel dengesizlikler yaratmaksızın geri kalmış bölgelerin teşvik edilmesi ve bu bölgelere sanayi yatırımlarının çekilmesidir. $\mathrm{Bu}$ nedenle, düşük gelişme seviyesine sahip bölgelerdeki OSB'lerin durumunun değerlendirilmesi önemlidir. 
$\mathrm{Bu}$ çalışmada Doğu Anadolu Projesi Bölge Kalkınma İdaresinde yer alan OSB'lerin etkinliği VZA ve VZA temelli modeller uygulanarak analiz edilecektir. Çalışmada kullanılan veriler Bilim, Sanayi ve Teknoloji Bakanlığı'nın sanayi bölgelerinden sorumlu birimi olan Endüstri Bölgeleri Genel Müdürlüğü ve Bilim, Sanayi ve Teknoloji Bakanlığı'nın önemli bilgi sistemlerinden biri olan Kurumsal Bilgi Sisteminden elde edilmiştir. Bu bilgi sistemlerinde
OSB'lerle ilgili son veriler 2015 yılına aittir, bu nedenle çalışma 2015 için yapılmıştır.

Çalışmada, "toplam sanayi parsel alanı" ve "toplam parsel sayısı" girdi olarak kabul edilirken "firma sayısı", "istihdam", "net satışlar" ve "İhracat hacmi" çıktı olarak ele alınmıştır. OSB'lere ilişkin girdi ve çıtıtı verileri Tablo 1'de verilmektedir.

Tablo 1. OSB'ler için girdi ve çıktı verileri

\begin{tabular}{|l|l|l|l|l|l|l|}
\hline OSB & $\begin{array}{l}\text { Toplam } \\
\text { sanayi } \\
\text { parsel alanı } \\
\text { (Ha) }\end{array}$ & $\begin{array}{l}\text { Toplam } \\
\text { parsel sayısı }\end{array}$ & Firma sayısı & İstihdam & Net satışlar (TL) & İhracat hacmi (\$) \\
\hline Bingöl & 38.53 & 45 & 21 & 600 & 53670669 & 186901 \\
\hline Elazı̆̆ & 304.10 & 219 & 114 & 2645 & 816716123 & 10954104 \\
\hline Erzincan & 310.64 & 213 & 63 & 1430 & 1838069842 & 7465403 \\
\hline Erzurum-Merkez I & 107.00 & 117 & 98 & 4177 & 3616575314 & 42515144 \\
\hline Iğdır & 83.65 & 105 & 15 & 165 & 57472776 & 747874 \\
\hline Kars & 103,79 & 93 & 52 & 530 & 499842564 & 21919 \\
\hline Malatya Merkez I & 1.099 .00 & 510 & 147 & 8850 & 2269074784 & 153413164 \\
\hline Malatya II & 300.00 & 156 & 121 & 6588 & 1192030117 & 108473377 \\
\hline Van & 85.20 & 137 & 86 & 1750 & 441521400 & 2914561 \\
\hline
\end{tabular}

İlk olarak veriler doğrusal normalizasyon prosedürü kullanılarak normalize edilmiştir. Girdi verileri $x_{i j} / x_{i}^{*}$ olarak, çıktı verileri ise $y_{r j} / y_{r}^{*}$ şeklinde normalize edilmiştir. $\mathrm{Bu}$ gösterimlerde $x_{i}^{*}=\max _{j} x_{i j}, \quad \forall i$ ve $y_{r}^{*}=\max _{j} y_{r j}, \quad \forall r$ olarak ifade edilmektedir. Normalize edilmiş veriler Tablo 2'de gösterilmektedir.

Tablo 2. OSB'ler için normalize edilmiş girdi ve çıtıtı verileri

\begin{tabular}{|l|l|l|l|l|l|l|}
\hline OSB & $\begin{array}{l}\text { Toplam sanayi } \\
\text { parsel } \begin{array}{l}\text { alanı } \\
\text { (Ha) }\end{array}\end{array}$ & $\begin{array}{l}\text { Toplam } \\
\text { parsel sayıs1 }\end{array}$ & Firma sayıs1 & İstihdam & $\begin{array}{l}\text { Net satışlar } \\
(\mathrm{TL})\end{array}$ & $\begin{array}{l}\text { İhracat hacmi } \\
(\$)\end{array}$ \\
\hline Bingöl & 0.035059145 & 0.088235294 & 0.142857143 & 0.06779661 & 0.014840 & 0.001218 \\
\hline Elazığ & 0.276706096 & 0.429411765 & 0.775510204 & 0.298870056 & 0.225826 & 0.071403 \\
\hline Erzincan & 0.282656961 & 0.417647059 & 0.428571429 & 0.161581921 & 0.508235 & 0.048662 \\
\hline Erzurum-Merkez I & 0.097361237 & 0.229411765 & 0.666666667 & 0.471977401 & 1.000000 & 0.277128 \\
\hline Iğdır & 0.07611465 & 0.205882353 & 0.102040816 & 0.018644068 & 0.015891 & 0.004875 \\
\hline Kars & 0.0944404 & 0.182352941 & 0.353741497 & 0.059887006 & 0.138209 & 0.000143 \\
\hline Malatya-Merkez I & 1 & 1 & 1 & 1 & 0.627410 & 1 \\
\hline Malatya II & 0.272975432 & 0.305882353 & 0.823129252 & 0.74440678 & 0.329602 & 0.707067 \\
\hline Van & 0.077525023 & 0.268627451 & 0.585034014 & 0.197740113 & 0.122083 & 0.018998 \\
\hline
\end{tabular}

GAMS programlama dili kullanılarak VZA ve VZA temelli modeller çözülmüş ve Doğu 
Anadolu Projesi Bölge Kalkınma İdaresinde yer alan OSB'ler için etkinlik değerleri Tablo 3'teki

gibi elde edilmiştir.

Tablo 3. Doğu Anadolu Projesi Bölge Kalkınma İdaresinde yer alan OSB'ler için etkinlik değerleri

\begin{tabular}{|c|c|c|c|c|c|c|c|c|c|c|}
\hline OSB & $\begin{array}{l}\text { VZA-CCR } \\
\text { modeli } \\
\text { etkinlik } \\
\text { değeri }\end{array}$ & $\begin{array}{l}\text { VZA- } \\
\text { CCR } \\
\text { modeli } \\
\text { siralama }\end{array}$ & $\begin{array}{l}\text { MinSum } \\
\text { modeli } \\
\text { etkinlik } \\
\text { değeri }\end{array}$ & $\begin{array}{l}\text { MinSu } \\
\text { m } \\
\text { modeli } \\
\text { siralama }\end{array}$ & $\begin{array}{l}\text { MiniMax } \\
\text { modeli } \\
\text { etkinlik } \\
\text { değeri }\end{array}$ & $\begin{array}{l}\text { MiniMax } \\
\text { modeli } \\
\text { siralama }\end{array}$ & $\begin{array}{l}\text { Süper etkinlik } \\
\text { modeli } \\
\text { etkinlik değeri }\end{array}$ & $\begin{array}{l}\text { Süper } \\
\text { etkinlik } \\
\text { modeli } \\
\text { siralama }\end{array}$ & $\begin{array}{lr}\text { Ortak } & \text { ağırlık } \\
\text { tabanlı } & \text { VZA } \\
\text { modeli } & \text { etkinlik } \\
\text { değeri } & \end{array}$ & \begin{tabular}{|l} 
Ortak \\
ağırlık \\
tabanlı \\
VZA \\
modeli \\
siralama
\end{tabular} \\
\hline Bingöl & 0.58642 & 6 & 0.516264 & 6 & 0.026316 & 8 & 0.586419 & 6 & 0.142857 & 6 \\
\hline Elazı̆g & 0.621468 & 5 & 0.585227 & 5 & 0.128328 & 5 & 0.621469 & 5 & 0.159351 & 5 \\
\hline Erzincan & 0.353118 & 8 & 0.333891 & 8 & 0.196626 & 4 & 0.353118 & 7 & 0.090543 & 7 \\
\hline $\begin{array}{l}\text { Erzurum- } \\
\text { Merkez I }\end{array}$ & 1 & 1 & 1 & 1 & 1 & 1 & 5.959561 & 1 & 0.25641 & 1 \\
\hline Iğdır & 0.189697 & 9 & 0.159246 & 9 & 0.018563 & 9 & 0.189698 & 9 & 0.043732 & 9 \\
\hline Kars & 0.667542 & 4 & 0.617585 & 4 & 0.095619 & 6 & 0.667544 & 4 & 0.171165 & 4 \\
\hline $\begin{array}{l}\text { Malatya- } \\
\text { Merkez I }\end{array}$ & 0.452887 & 7 & 0.380353 & 7 & 0.452888 & 3 & 0.452888 & 8 & 0.088235 & 8 \\
\hline Malatya II & 1 & 1 & 1 & 1 & 1 & 1 & 1.913553 & 2 & 0.237441 & 2 \\
\hline Van & 1 & 1 & 0.697687 & 3 & 0.083608 & 7 & 1.102087 & 3 & 0.192164 & 3 \\
\hline
\end{tabular}

Etkinlik skorları ve sıralamalarda görüldüğü gibi, geleneksel VZA-CCR modeli, mimsum ve minimax etkinlik modellerinin sonuçlarına göre, Doğu Anadolu Projesi Bölge Kalkınma İdaresinde etkin birden fazla etkin OSB bulunmaktadır. Minimax etkinlik modeli, geleneksel VZA-CCR modeline ve minsum modeline göre elde edilen etkin OSB sayısını azaltmasına rağmen, bu sayı genel olarak bir taneye indirilememektedir. Dahas1, modellerin KVB arasinda ayırım yapma gücü düşüktür ve tüm etkin OSB'ler ilk sırada yer almaktadır. Öte yandan, süper etkinlik modeli ve ortak ağırlık tabanlı VZA modelinin sonuçlarına göre en etkin OSB bulunmaktadır. KVB'ler arasında ayırım gücünün yüksek olması ve değişkenler için ortak ağırlıklar kullanması nedeniyle, ortak ağırlık tabanlı VZA modelinin sonuçları referans olarak alınmaktadır. Sonuçlara göre, Doğu Anadolu Projesi Bölge Kalkınma İdaresinde yer alan en etkin 3 OSB ErzurumMerkez I, Malatya II, Van olarak, etkinlik değeri en düşük olan 3 OSB ise Erzincan, Malatya Merkez I ve Iğdır olarak belirlenmiştir.

\section{Sonuç}

Endüstriyel gelişme ve dengeli bölgesel kalkınma sağlamayı, kentleşme ile sanayileşme arasındaki ilişkileri düzenleyerek çevre sorunlarını çözmeyi ve daha düşük maliyetli altyapı hizmetleri sunmayı amaçlayan OSB'ler, Türkiye'de planlı kalkınma döneminde kurulmaya başlanmıştır. Ancak, günümüzde OSB'lerin doluluk ve üretime geçiş oranlarının yeterli olmadığı görülmektedir.
Bu nedenle OSB'ler için etkinlik analizi yapılması ihtiyaç haline gelmiştir.

Literatürde var olan çalışmalar incelendiğinde OSB etkinlik analizi gerçekleştiren bir çalışmaya rastlanmamaktadır. Analizin ve elde edilen sonuçların güvenilirliğini arttırmak ve bölgesel farklılıklardan kaynaklanan etkileri en aza indirgemek amaciyla OSB'lerin etkinlik analizinin bölgesel bazda yapılması gerekmektedir. $\mathrm{Bu}$ bağlamda, çalışmada, geleneksel VZA_CCR modeli, minsum ve minimak etkinlik modelleri ve ortak ağırlık tabanlı VZA modeli kullanılarak Doğu Anadolu Projesi Bölge Kalkınma İdaresinde yer alan OSB'ler için etkinlik analizi gerçekleştirilmiş ve elde edilen sonuçlar kıyaslanmıştır.

VZA_CCR modeline göre etkin çıkan OSB'ler Erzurum-Merkez I, Malatya II ve Van iken Minsum ve Minimax modellerine göre ErzurumMerkez I ve Malatya II olarak belirlenmiştir. Geleneksel VZA-CCR modeli, mimsum ve minimax etkinlik modelleri OSB'leri etkin ve etkin olmayan olarak iki gruba ayırmış ve tam bir sıralama belirleyememiştir. $\mathrm{Bu}$ modellerin sonuçlarına göre, Doğu Anadolu Projesi Bölge Kalkınma İdaresinde birden fazla etkin OSB bulunmaktadır. $\mathrm{Bu}$ modellerin KVB arasında ayırım yapma gücü düşüktür ve tüm etkin OSB'ler ilk sırada yer almaktadır. Bu nedenle çalışmada süper etkinlik modeli ve ortak ağırlık tabanlı VZA modeli de kullanılmış ve OSB'ler için tek bir sıralama elde edilmiştir. Buna göre, Erzurum-Merkez I, en etkin OSB olarak 
belirlenmiş ve onu sırasıyla Malatya II ve Van takip etmiştir. Malatya-Merkez I ve Iğdır OSB'leri ise etkinlikleri en düşük OSB'ler olarak belirlenmiştir.

VZA, karar verme sürecinde yönetsel amaçlar için kullanılabilecek önemli bilgiler sağlamaktadır. Bu çalışmada, "toplam sanayi parsel alanı" ve "toplam parsel sayısı" girdi olarak, "firma sayısı", "istihdam", "net satışlar" ve "İhracat hacmi" ise çıktı olarak ele alınmış ve Doğu Anadolu Projesi Bölge Kalkınma İdaresinde yer alan organize sanayi bölgelerinin etkinlikleri değerlendirilmiştir. Sonuçlara göre Erzurum-Merkez I, Malatya II ve Van en etkin faaliyet gösteren üç OSB olarak belirlenmiştir. Temel VZA nosyonuna göre, girdilerin en aza indirgenmesi ve aynı zamanda çıktıların en büyüklenmesi hedeflenmektedir. Dolayısıyla, OSB'lerin verimli bir şekilde çalışması, toplam sanayi parsel alanının ve toplam parsel sayisinin en aza indirilmesi ile gerçekleştirilmekte ve aynı zamanda üretimdeki firma sayısının, net satışların ve ihracat hacminin maksimize edilmesi, tüm ülkede üretim hacmini ve sürdürülebilirliğini arttırmaktadır. Öte yandan, önerilen model, "istihdam" düzeyini en üst seviyeye çıkarılacak bir çıktı olarak göz önünde bulundurarak istihdam firsatlarını desteklemektedir. En etkin OSB'lerin verileri incelendiğinde toplam sanayi parsel alanı ve toplam parsel sayısı değerlerinin arzu edildiği gibi oldukça düşük olduğu, çıktı değerlerinin ise diğer OSB'lere göre yüksek olduğu görülmektedir. Etkinlik sıralamasında en son sırada yer alan Iğdır OSB için girdi değerleri düşük olmasına rağmen çıktı değerlerinin de oldukça düşük olması bu OSB'nin etkinlik değerinin düşük çıkmasına neden olmuştur. Malatya-Merkez I için ise çıktı değerlerinin yüksek olmasına rağmen girdi değerlerinin de oldukça yüksek olması bu OSB'nin etkin olmayan OSB'ler arasinda yer almasına neden olmuştur.

Gelecek çalışmalarda, Türkiye'nin diğer coğrafi bölgelerinde kurulmuş olan OSB'ler için etkinlik analizleri gerçekleştirilebilir.

\section{Kaynaklar}

Adler, N., Friedman, L. ve Sinuany-Stern, Z., 2002. Review of ranking methods in the data envelopment analysis context, European Journal of Operational Research, 140(2), 249-265.

Andersen, P. ve Petersen, N.C., 1993. A procedure for ranking efficient units in data envelopment analysis, Management Science, 39, 1261-1264.
Cansız, M., 2010, Türkiye'de Organize Sanayi Bölgeleri Politikaları ve Uygulamaları, Korza Basımevi, Ankara, 1-154s.

Charnes, A., Cooper, W.W., Lewin, A.Y., Seiford, L.M., 1994, Basic DEA models, Data Envelopment Analysis: Theory, Methodology, and Applications, Springer, Netherlands, 23$47 \mathrm{~s}$.

Charnes, A., Cooper, W.W. ve Rhodes, E., 1978. Measuring the efficiency of decision making units, European Journal of Operational Research, 2(6), 429-444.

Chen, N., Xu, L. ve Chen, Z., 2017. Environmental efficiency analysis of the Yangtze River Economic Zone using super efficiency data envelopment analysis (SEDEA) and TOBIT models, Energy, 134, 659-671.

Façanha, L.O. ve Resende, M., 2004. Price cap regulation, incentives and quality: The case of Brazilian telecommunications, International Journal of Production Economics, 92(2), 133144.

Fan, Y., Bai, B.B., Qiao, Q., Kang, P., Zhang, Y. ve Guo, J., 2017. Study on eco-efficiency of industrial parks in China based on data envelopment analysis, Journal of Environmental Management, 192, 107-115.

Fried, H.O., Schmidt, S.S. ve Syaisawarng, S., 1999. Incorporating the Operating Environment into a Nonparametric Measure of Technical Efficiency, Journal of Productivity Analysis, 12(3), 249-267.

Hu, J.L., Han, T.F., Yeh, F.Y. ve Lu, C.L., 2010. Efficiency of Science and Technology Industrial Parks in China, Journal of Management Research, 10( 3), 151-166.

Hu, J.L., Yeh, F.Y. ve Chang, I.T., 2009. Industrial park efficiency in Taiwan, Journal of Information and Optimization Sciences, 30(1), 63-86.

Izadikhah, M. ve Saen, R.F., 2015. A new data envelopment analysis method for ranking decision making units: An application in industrial parks, Expert Systems, 32(5), 596608.

Khodakarami, M., Shabani, A. ve Saen, R.F., 2014. A new look at measuring sustainability of industrial parks: a two-stage data envelopment analysis approach, Clean Techn Environ Policy, 16(8), 1577-1596.

Li, X.B. ve Reeves, G.R., 1999. A multiple criteria approach to data envelopment analysis, 
European Journal of Operational Research, 115(3), 507-517.

Liu, W., Tian, J., Chen, L., Lu, W. ve Gao Y., 2015. Environmental Performance Analysis of EcoIndustrial Parks in China: A Data Envelopment Analysis Approach, Journal of Industrial Ecology, 19(6), 1070-1081.

Yolalan, R., 1993, İşletmeler aras göreli etkinlik ölçümü, Milli Produktivite Merkezi Yayınları, Ankara, 483s.

Sun, J., Wu, J. ve Guo, D., 2013, Performance ranking of units considering ideal and anti-ideal DMU with common weights, Applied Mathematical Modelling, 37(9), 6301-6310.
URL-1, Bilim, Sanayi ve Teknoloji Bakanlığı Sanayi Bölgeleri Genel Müdürlüğü web sitesi, http://kss.sanayi.gov.tr/. 3 Mart 2016.

URL-2, Mevzuat Bilgi Sistemi, http://www.mevzuat.gov.tr/Metin1.Aspx?Mevz uatKod $=1.5 .4562 \&$ MevzuatIliski $=0 \&$ sourceXm 1 Search $=\&$ Tur $=1 \&$ Tertip $=5 \& \mathrm{No}=4562$. Mayıs 2016.

Yenilmez, F. ve Girginer, N., 2012. Assessing export performance of textile companies in Eskisehir Organized Industrial Zone by use of data envelopment analysis (DEA), Tekstil ve Konfeksiyon, 22(1), 12. 